\title{
The Race-Specific Resistance Gene to Powdery Mildew, MlRE, Has a Residual Effect on Adult Plant Resistance of Winter Wheat Line RE714
}

\author{
N. Chantret, M. T. Pavoine, and G. Doussinault
}

I.N.R.A. Station d'Amélioration des Plantes, Domaine de la Motte, BP 29, 35653 Le Rheu cedex, France. Accepted for publication 29 March 1999.

\begin{abstract}
Chantret, N., Pavoine, M. T., and Doussinault, G. 1999. The race-specific resistance gene to powdery mildew, MIRE, has a residual effect on adult plant resistance of winter wheat line RE714. Phytopathology 89:533-539.

Race-specific resistance genes to powdery mildew have been extensively used in wheat breeding programs, but the complete resistance they provide breaks down when confronted by pathogen isolates with matching virulence. However, when overcome, some race-specific genes have a residual action leading to a reduction of the symptoms. Our objective

resistance (VPR) in the line RE714. Individuals from two populations (double haploid $[\mathrm{DH}]$ and $\mathrm{F}_{3}$ families) were genotyped for the race-specific genes $M l R E$ and $P m 4 b$ and assessed for their resistance under field conditions at the adult plant stage (in 1996 and 1997 for the DH lines and in 1997 for the $\mathrm{F}_{3}$ families). Vernalized seedlings of the $\mathrm{DH}$ population were tested with four powdery mildew isolates. Only the $M I R E$ gene had a significant effect (dominant type) on APR. Neither $M I R E$ nor Pm4b had a significant effect on VPR. The dominant residual effect of the defeated race-specific gene $M I R E$ was a component of APR in the line RE714.
\end{abstract} was to determine if the resistance genes MlRE and $P m 4 b$ have a residual effect on adult plant resistance (APR) and on vernalized seedling plant

Powdery mildew of wheat (Triticum aestivum), caused by Blumeria graminis (DC.) E.O. Speer f. sp. tritici Ém. Marchal (synonym = Erysiphe graminis DC. f. sp. tritici Ém. Marchal), is economically significant in areas of Europe with a high maritime rainfall or semicontinental climate (3). Effective fungicide treatments exist but their efficacy is rapidly overcome, and use of resistant cultivars is a more economic and environmentally sensitive method of control (9).

The best known system of resistance to powdery mildew in wheat is qualitative and race specific. It is effective against some isolates of powdery mildew but ineffective against others, with clear-cut differences between susceptible and resistant cultivars. This resistance is controlled by single genes (19). Currently, 24 resistance loci, with or without different allelic forms, have been assigned to specific chromosomes $(11,14)$. These genes follow the gene-forgene model described by Flor (8). Incompatibility (i.e., resistance of the host) requires the simultaneous presence of the resistance allele in the host and of the corresponding avirulence allele in the pathogen. The majority of these race-specific genes are expressed from the seedling stage (two leaves), but some of them such as Pm5 or Pm6 are only fully expressed from the four- to five-leaf growth stage (12). In breeding programs, race-specific genes have been extensively used, but most of them are generally rapidly overcome by the pathogen.

Another system of resistance exists but needs to be better understood before it can be used effectively by breeders. This resistance is quantitative and has been detected in cultivars without identified race-specific genes or in which known race-specific genes have been overcome by the pathogen. Quantitative resistance is much more complex; it has been studied in different ways on different plant material. Quantitative resistance has usually been observed at the adult plant stage in the field under natural powdery mildew infection. This resistance is characterized by delayed infection and reduced growth and reproduction of the pathogen and is

Corresponding author: N. Chantret; E-mail address: chantret@ rennes.inra.fr

Publication no. P-1999-0510-01R

(C) 1999 The American Phytopathological Society
Additional keywords: Blumeria graminis f. sp. tritici, residual expression. most commonly described as "slow mildewing," "adult plant resistance" $(9,24)$, or "partial resistance" $(7,10)$. However, Bennett $(1,2)$ observed these effects at both the seedling and adult plant stages with a population of powdery mildew and named it "background resistance." Other authors worked on seedlings with pure isolates and described the components of rate-reducing resistance (22).

With quantitative resistance, evidence for the existence of specific components has not been clearly demonstrated. For some cultivars, no race-specific effects have been detected in partial resistance (7). However, other studies have shown specific interactions between some components of slow mildewing and the isolates chosen (22).

Race-specific resistance genes and quantitative resistance are considered to be independent. However, investigations of the relationship between them suggested another kind of expression for race-specific genes when they are defeated. This has been termed residual expression. Martin and Ellingboe (13) showed that the level of compatibility that occurred with a virulent isolate was different in lines possessing Pm4a than in near-isogenic lines without Pm4a (when characters other than final infection type were observed). Nass et al. (15) showed that some defeated race-specific genes had residual ability to restrict disease increase and disease severity. Moreover, in these cases of residual expression, race-specific differential interactions with compatible isolates occurred (23).

The line RE714 possesses two independent, race-specific genes: $P m 4 b$ (dominant gene, already described) and MlRE (recessive gene, recently identified) (20). This line expressed adult plant resistance (APR) in field tests over several years in the west of France (21) where $P m 4 b$ and $M l R E$ resistance genes have been recently overcome. 'RE714' also shows resistance at the vernalized seedling plant stage (VPR) with some isolates carrying virulent genes against $M I R E$ and $P m 4 b$. Our aim was to investigate whether defeated racespecific genes MIRE and Pm4b may be involved in APR or in resistance at an intermediate stage of plant development (vernalized seedlings). Segregating populations were genotyped for these racespecific resistance genes and assessed for VPR and APR in the field. The effects of both $M l R E$ and $P m 4 b$ genes on VPR and APR were tested. 


\section{MATERIALS AND METHODS}

Plant material. Forty-four double haploid (DH) lines, produced using anther culture (Hybrinova Inc., Pouy Roquelaure, France; Agrogène Inc., Moissy Cramayel, France) and $140 \mathrm{~F}_{3}$ families, both derived from a cross between 'RE714' (resistant line) and 'Hardi' (a susceptible cultivar that does not possess any race-specific genes), were used.

'Renan', which possesses the race-specific resistance gene $P m 4 b$, and 'Triticum dicoccum 119', the donor of MIRE (20), were used as the control lines for the corresponding genes in seedling tests and in the analysis of the composition of the natural powdery mildew populations. Two of the DH lines from the cross between 'RE716' and 'Hardi', 'DH196' and 'DH5', observed in a hillplot trial in 1996 were chosen as control lines in the 1997 raw trial. 'DH196' possesses the MIRE and Pm4b genes and exhibits a high level of APR, while 'DH5' possesses no race-specific gene and has an intermediate level of APR.

Fungal material. The eight $B$. graminis f. sp. tritici isolates used for seedling and vernalized seedling tests were single-pustule progenies with known virulence response to the resistance genes $P m 4 b$ and MlRE (Table 1). They were collected in France from 1989 to 1996. Isolates used for the seedling tests were different than those used for the vernalized seedling tests (described below).

Adult plant tests were conducted in the field under natural epidemics of powdery mildew. In 1997, the local population of powdery mildew was analyzed for virulence gene frequencies matching MlRE and Pm4b. Seedlings of 'RE714', 'Renan', 'Hardi', and 'T. dicoccum 119' were maintained for $4 \mathrm{~h}$ in the field and evaluated after incubation at $16^{\circ} \mathrm{C}$ in a mildew-proof growth room $\left(16^{\circ} \mathrm{C}, 16 \mathrm{~h}\right.$ of daylight, $140 \mu \mathrm{E} / \mathrm{m}^{2} / \mathrm{s}$ ) for 11 days. Colonies on the primary leaves of five plants for each line were counted, and the ratio with the susceptible control 'Hardi' was calculated. This method allowed us to estimate the minimal frequency of the two virulence genes. In 1996, the presence of the two corresponding virulence genes in the natural population of powdery mildew was monitored with the same method, but gene frequencies were not calculated.

Disease assessments for the seedling tests. To genotype the plants for race-specific genes, four isolates were chosen according to their ability to reveal $P m 4 b, M l R E$, or both (Table 1). Plants were inoculated and scored on a 0 to 9 scale $(0=$ no visible symptoms to 9 = heavy sporulation) based on infection type, number of colonies, and intensity of sporulation, as previously described (20). Each DH line was tested with isolates BZ, 95-9, and 95-46 in three replicates (Table 1). The $\mathrm{F}_{2}$ parental plants were genotyped by testing $13 \mathrm{~F}_{3}$ plants. The $\mathrm{F}_{3}$ plants were tested (without replicates) with isolates 93-27 and BZ. 93-27 was the isolate with which the MIRE gene was originally identified by Robe and Doussinault (20). The risk of not detecting the least frequent phenotype when testing $13 \mathrm{~F}_{3}$ progeny from a heterozygous $\mathrm{F}_{2}$ plant is $2 \%$.

Disease assessments for the vernalized seedling tests. Vernalized seedling tests were originally perfected with the objective of predicting APR. The process of testing was similar to that used for the seedling test, except for four major modifications. First, the seedlings were vernalized in a powdery mildew-proof climatized room for 27 days at $0^{\circ} \mathrm{C}\left(12 \mathrm{~h}\right.$ of daylight, $\left.140 \mu \mathrm{E} / \mathrm{m}^{2} / \mathrm{s}\right)$ followed by 36 days at $9^{\circ} \mathrm{C}\left(18 \mathrm{~h}\right.$ of daylight, $\left.140 \mu \mathrm{E} / \mathrm{m}^{2} / \mathrm{s}\right)$ and were at the five-leaf growth stage when inoculated. Second, leaf segments were cut from the third leaf instead of from the first leaf. Third, a higher concentration of benzimidazole (100 mg/liter) was

TABLE 1. Reactions at seedling stage of control lines 'RE714' (MIRE and Pm4b), 'Renan' (Pm4b), 'Triticum dicoccum 119' (MIRE), and 'Hardi' (as susceptible parent without race-specific gene) tested with isolates used for seedling and vernalized seedling tests

\begin{tabular}{|c|c|c|c|c|c|c|c|c|}
\hline \multirow[b]{2}{*}{ Control line } & \multicolumn{4}{|c|}{ Isolates used for seedling tests } & \multicolumn{4}{|c|}{ Isolates used for vernalized seedling test } \\
\hline & $\mathrm{BZ}$ & $93-27$ & $95-9$ & $95-46$ & $96-22$ & $95-44$ & $96-47$ & $93-25$ \\
\hline RE714 $(M l R E+P m 4 b)$ & $a v^{a}$ & av & av & av & $\mathrm{v}$ & $\mathrm{v}$ & $\mathrm{V}$ & $\mathrm{v}$ \\
\hline Renan $(P m 4 b)$ & av & $\mathrm{v}$ & $\mathrm{v}$ & av & $\mathrm{v}$ & $\mathrm{V}$ & $\mathrm{v}$ & $\mathrm{v}$ \\
\hline T. dicoccum. 119 (MlRE) & $\mathrm{V}$ & av & av & av & $\ldots$ & $\ldots$ & $\ldots$ & $\ldots$ \\
\hline Hardi & $\mathrm{v}$ & $\mathrm{v}$ & $\mathrm{v}$ & $\mathrm{v}$ & $\mathrm{v}$ & $\mathrm{v}$ & $\mathrm{v}$ & $\mathrm{V}$ \\
\hline
\end{tabular}

$\mathrm{a}$ av $=$ Avirulent, $\mathrm{v}=$ virulent, and $\ldots=$ not tested.

TABLE 2. Number of $F_{2}$ parental plants and double haploid lines obtained from the cross between 'RE714' and 'Hardi' for each possible combination of alleles at the $P m 4 b$ and $M I R E$ resistance loci ${ }^{\mathrm{a}}$

\begin{tabular}{|c|c|c|c|c|c|c|c|}
\hline \multirow[b]{2}{*}{ Progeny } & \multicolumn{5}{|c|}{ Genotypic class } & \multirow[b]{2}{*}{ Hypothesis tested } & \multirow[b]{2}{*}{$P\left(\chi^{2}\right)$ value } \\
\hline & $P m 4 b / P m 4 b$ & $P m 4 b / \mathrm{o}^{\mathrm{b}}$ & MIRE/MIRE & MIRE/o & $\mathrm{o} / \mathrm{o}$ & & \\
\hline DH & 26 & $\ldots^{c}$ & & & 18 & $1: 1$ & 0.23 \\
\hline $\mathrm{F}_{2}$ & 38 & 68 & & & 34 & $1: 2: 1$ & 0.84 \\
\hline DH & & & 21 & $\cdots$ & 23 & $1: 1$ & 0.76 \\
\hline $\mathrm{F}_{2}$ & & & 25 & 77 & 38 & $1: 2: 1$ & 0.15 \\
\hline
\end{tabular}

a The fit of observed distributions to theoretical segregation ratios is given as the probability of the chi-square value $\left(P\left[\chi^{2}\right]\right)$.

b o = Allele of the susceptible parent 'Hardi" corresponding to Pm4b or MIRE.

${ }^{\mathrm{c}}$ Unexpected class for the double haploid lines.

TABLE 3. Number of $\mathrm{F}_{2}$ parental plants and double haploid lines obtained from the cross between 'RE714' and 'Hardi' for each possible combination of alleles at the $P m 4 b$ and $M l R E$ resistance loci ${ }^{\mathrm{a}}$

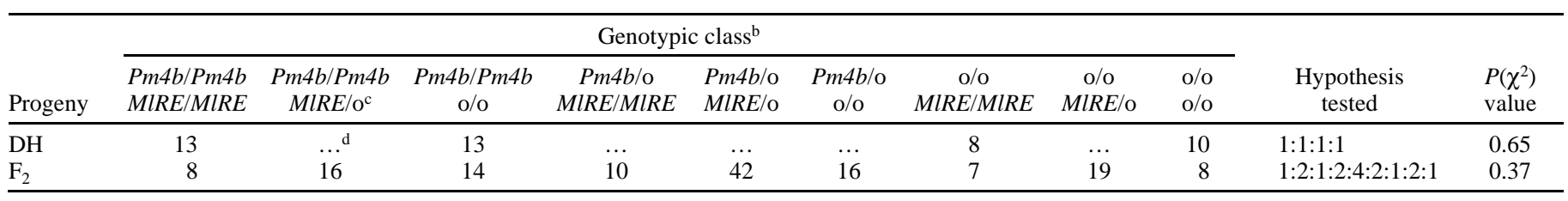

${ }^{a}$ The fit of observed distributions to theoretical segregation ratios is given as the probability of the chi-square value $\left(P\left[\chi^{2}\right]\right)$.

b The top line is the genotype at the Pm $4 b$ locus; the bottom line is the genotype at the MlRE locus.

${ }^{c} \mathrm{o}=$ Allele of the susceptible parent "Hardi" corresponding to Pm4b or MIRE.

${ }^{\mathrm{d}}$ Unexpected class for the double haploid lines. 
used in the agar on which leaf segments were kept. Fourth, all isolates used (Table 1) were virulent against 'RE714' at the seedling stage to reveal resistance components other than that conferred by seedling resistance genes.

Disease assessments of adult plants. Field trials were conducted in 1996 and 1997 to evaluate the resistance of the DH lines to the natural population of $B$. graminis f. sp. tritici at Le Rheu, France. The DH lines were sown as three replicate hillplots $(16 \mathrm{~cm}$ in diameter, 25 seeds per hillplot) separated from one another by $50 \mathrm{~cm}$. This method was only used for the $\mathrm{DH}$ lines, and it gave a high level of infection because of the high humidity levels inside the hillplots. The cultivar Barbee, very susceptible to all known races of $B$. graminis f. sp. tritici, was sown around the hillplots. The level of disease at the adult plant stage was scored on three different dates using a 1 to 9 scale based on observation inside each hillplot of sporulation intensity, leaf area covered by sporulating colonies, and distribution of symptoms along the plant (21).

$\mathrm{F}_{3}$ families were tested in the field in 1997 in a row design. Each of the $140 \mathrm{~F}_{3}$ families was sown on a row of 7 to 11 plants with about $15 \mathrm{~cm}$ between plants and $20 \mathrm{~cm}$ between rows. Rows
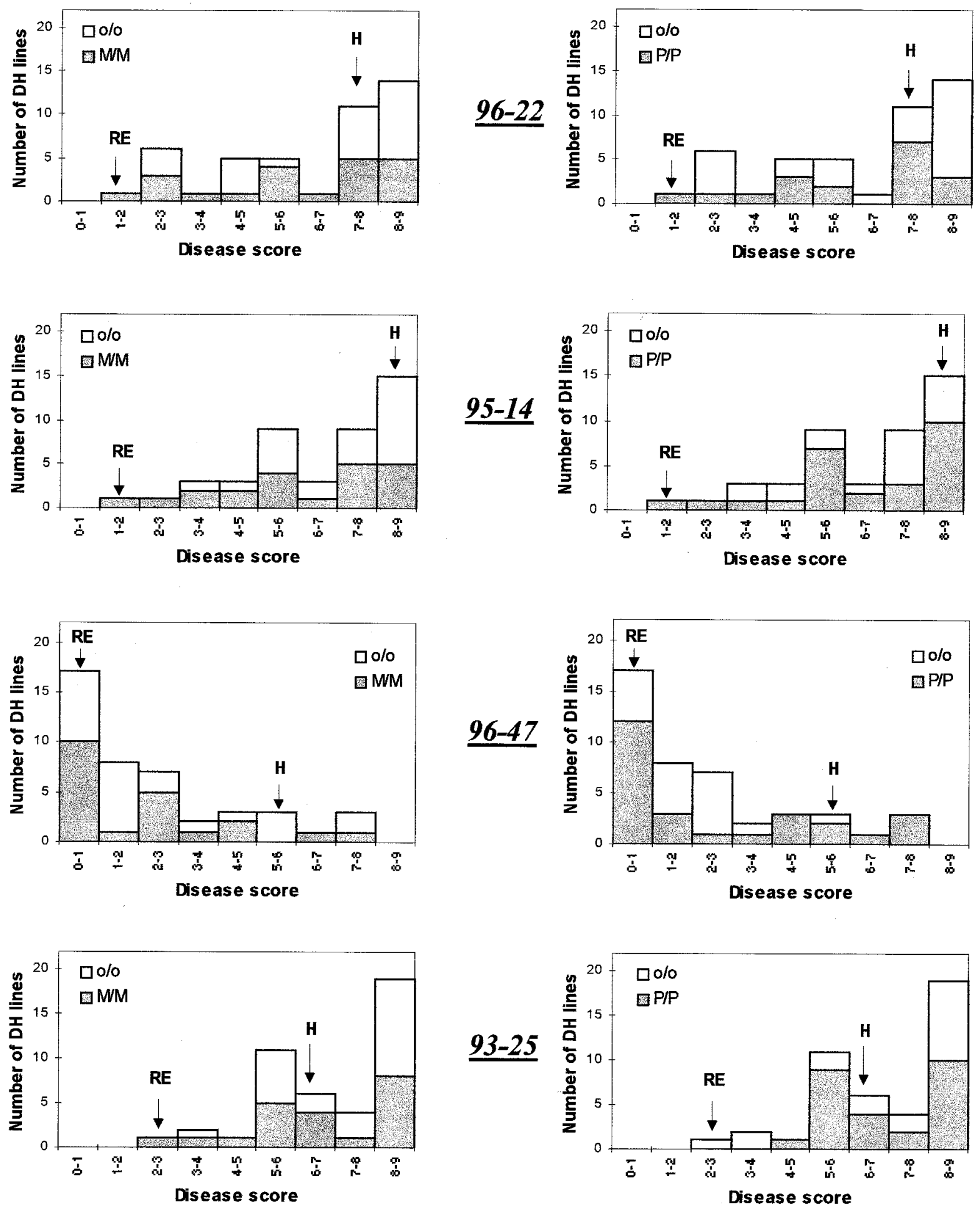

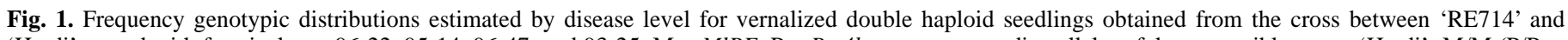

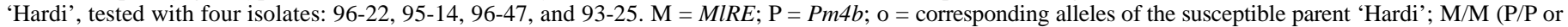
$\mathrm{o} / \mathrm{o})=$ homozygous for $M I R E(P m 4 b$ or o $)$, RE = 'RE714'; and $\mathrm{H}=$ 'Hardi'. 
were completely randomized in four plots, with 40 rows per plot (the fourth plot had only 20 rows because of experimental constraints). Four rows of control lines ('RE714', 'Hardi', 'DH196', and 'DH5') were uniformly distributed in each plot. One row of the susceptible 'Barbee' was included every two lines. This design was repeated twice. Three assessments were made for each plant using the 1 to 9 scale used in the hillplot trials.

Plants were sown in October and assessed in April and May for the DH lines and in May and June for the $\mathrm{F}_{3}$ families. Plants were approximately at the five-leaf stage at the first scoring and at the heading stage at the last scoring.

Data analysis. The six sets of field data from the DH lines (resistance assessments on three dates and for 2 years) were analyzed separately using a generalized linear model (Proc GLM of
Statistical Analysis System; SAS Institute, Cary, NC), according to the one-way analysis of variance model $Y_{i j}=\mu+G_{i}+R_{j}+e_{i j}$, in which $Y_{i j}$ is the score of genotype $i$ in replicate $j, \mu$ is the general mean, $G_{i}$ is the effect of genotype $i, R_{j}$ is the effect of replicate $j$, and $e_{i j}$ is the residual.

Predicted values were plotted against the corresponding residuals to verify their independence. A genotypic value was estimated for each DH line from the analysis of variance after adjusting for the replicate effect. The same method was used for the $\mathrm{F}_{3}$ families, using plot effect instead of replicate effect. Sixteen to twenty-two $\mathrm{F}_{3}$ plants per family were used to estimate one genotypic value per family after adjusting for the plot effect.

For each year, using the genotypic values, the area under the disease progress curve (AUDPC) was calculated for each DH line

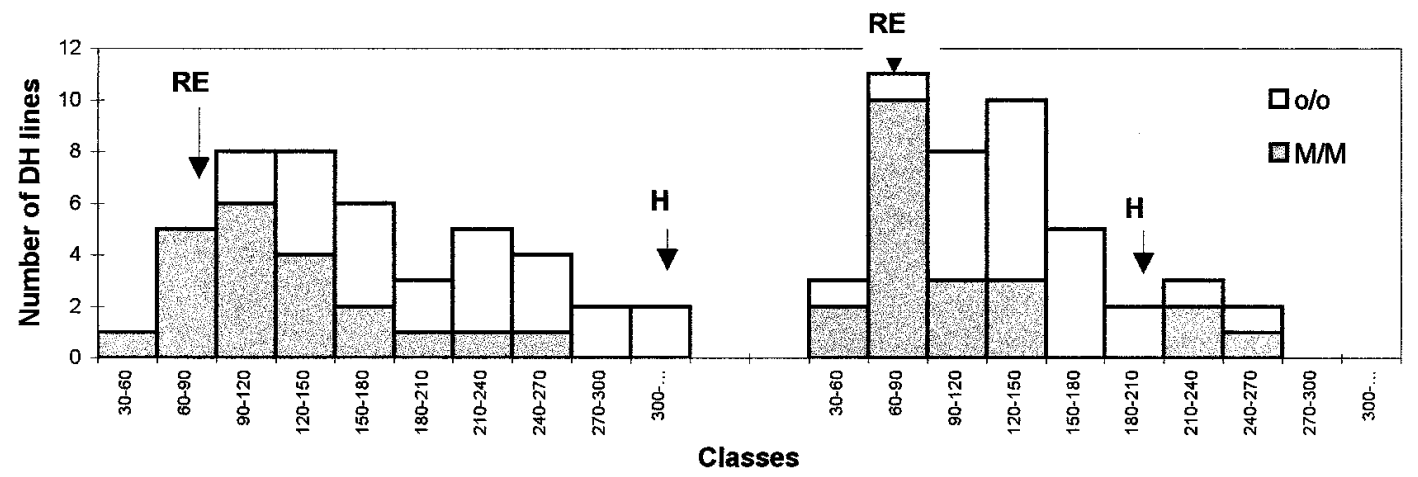

DH 1996

DH 1997

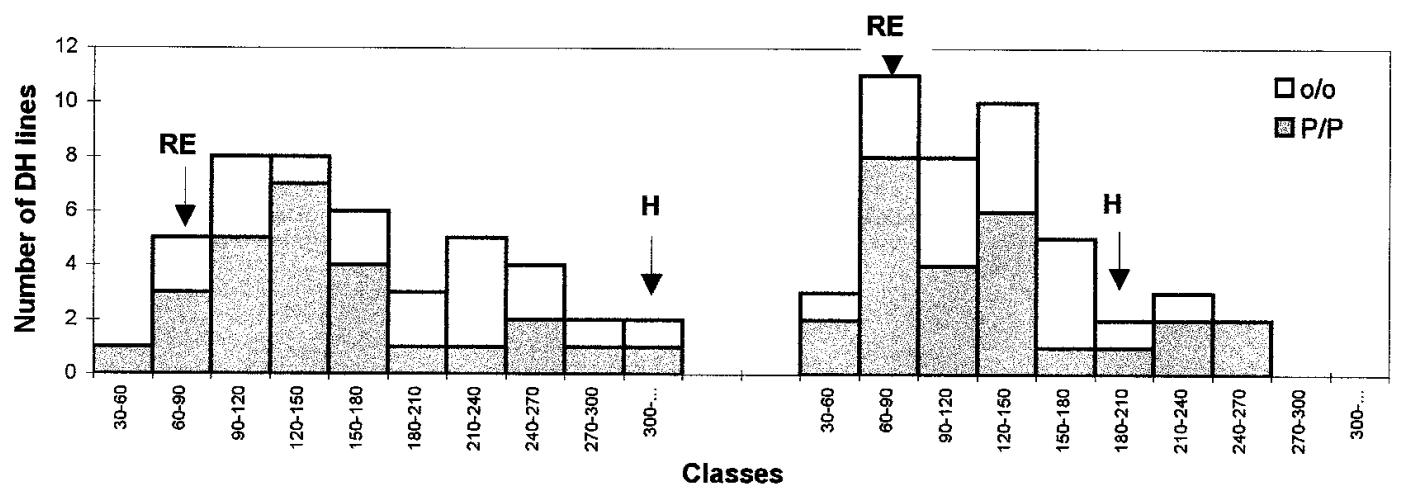

DH 1996

DH 1997
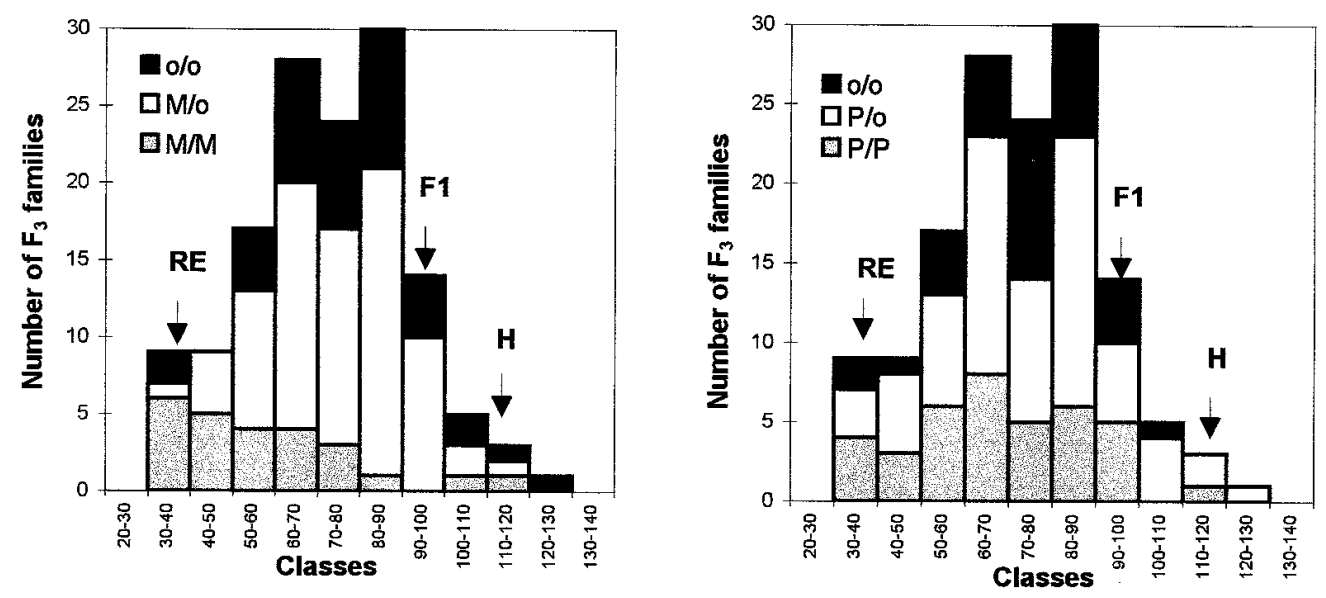

$F_{3}$ families 1997

Fig. 2. Frequency genotypic distributions estimated by area under the disease progress curve at adult plant stage for the double haploid lines (in 1996 and 1997) and for the $\mathrm{F}_{3}$ families (in 1997) obtained from the cross between 'RE714' and 'Hardi'. $\mathrm{M}=M I R E ; \mathrm{P}=P m 4 b ; \mathrm{o}=$ corresponding alleles of the susceptible parent 'Hardi'; M/M (P/P or o/o) = homozygous for MIRE (Pm4b or o); M/o (P/o) = heterozygous at the MlRE (Pm4b) locus; RE = 'RE714', and H = 'Hardi'. 
using the following formula: AUDPC $=\Sigma_{i}\left[\left(x_{i}+x_{i+1}\right) / 2\right] t_{i}$, in which $x_{i}$ is the genotypic values on date $i$ and $t_{i}$ is the time in days between dates $i$ and $i+1$ (4).

Evaluation of the effect of $M l R E$ and $P m 4 b$ on APR and VPR. When the data were suitable for analysis of variance, the following model was used: $Y_{i j k}=\mu+P_{i}+M_{j}+(P \cdot M)_{i j}+e_{i j k}$, in which $Y_{i j k}$ is the AUDPC value of individual $k$ with $P_{i}$ genotype at $P m 4 b$ locus and $M_{j}$ genotype at MIRE locus, $\mu$ is the general mean, $P_{i}$ is the effect of $P m 4 b, M_{j}$ is the effect of $M I R E,(P \cdot M)_{i j}$ is the interaction effect of $P m 4 b$ and $M l R E$, and $e_{i j k}$ is the residual.

$P_{i}$ and $M_{j}$ have two levels for the DH line and three for the $\mathrm{F}_{3}$ families. Means, adjusted by the least squares means method, were compared for significant factors with a Student-Fisher test. When predicted values and the corresponding residuals were not independent, nonparametric tests were made using the Wilcoxon method (Proc Npar1way, option Wilcoxon).

\section{RESULTS}

Seedling tests: Genotyping of the progenies. For each isolate, distributions of DH lines according to score classes from the seedling tests were clearly bimodal (data not shown); therefore, plants could be rated as resistant or susceptible. Minor differences between tests were probably caused, in part, by differences in inoculum density, which fluctuated from 200 to 600 spores per $\mathrm{cm}^{2}$ between experiments. The limit between resistant and susceptible classes was chosen according to the shape of the distribution and the scores of 'RE714' and ' $T$. dicoccum 119'.

According to classical methods of genotyping for race-specific genes, the $44 \mathrm{DH}$ lines were genotyped for MlRE and Pm4b (Table 2 ). The distribution of the DH lines into four classes corresponding to the four possible genotypes with two segregating genes is presented in Table 3. The ratio between the frequencies of the four possible genotypes confirmed the independence of $P m 4 b$ and MlRE $\left(P\left[\chi^{2}\right]=0.65\right)(20)$.

In the $\mathrm{F}_{3}$ tests, when $\mathrm{F}_{3}$ plants were all resistant (classes 0 to 3 ) or susceptible (classes 7 to 9 ) to isolates $93-27$ or $\mathrm{BZ}$, the $\mathrm{F}_{2}$ pa-

TABLE 4. Ratio of the number of spores with virulences matching $P m 4 b$ or $M I R E$ or both (evaluated on seedlings of corresponding control lines) to the total number of spores (evaluated on 'Hardi') in the natural powdery mildew population of the field in 1997 in the raw and hillplot trials

\begin{tabular}{llcc}
\hline Gene & \multicolumn{1}{c}{ Control line } & Raw trial (\%) & Hillplot trial (\%) \\
\hline MIRE $+P m 4 b$ & RE714 & $40 \pm 8$ & $32 \pm 3$ \\
$P m 4 b$ & Renan & $50 \pm 10$ & $68 \pm 12$ \\
MIRE & Triticum dicoccum 119 & $54 \pm 11$ & $60 \pm 9$ \\
None & Hardi & 100 & 100 \\
\hline
\end{tabular}

rental plant was interpreted as homozygous for the resistant or susceptible allele at the $M I R E$ or $P m 4 b$ locus. When a segregation was observed among plants of an $\mathrm{F}_{3}$ family, the $\mathrm{F}_{2}$ parental plant was interpreted as heterozygous.

So, for each gene (MlRE and $P m 4 b)$, the $\mathrm{F}_{2}$ parental plants were divided into three classes (Table 2). With the combined analysis of $\mathrm{BZ}$ and 93-27, the $\mathrm{F}_{2}$ parental plants were divided into nine classes. The number of plants in each class is presented in Table 3. Observed distributions of the $F_{2}$ parental plants in each class were compared with a theoretical segregation ratio by a chi-square test. The $P\left(\chi^{2}\right)$ values were 0.84 for $P m 4 b, 0.15$ for $M l R E$, and 0.37 for the segregation of both genes. The results were, therefore, in agreement with the previous results for the independence of these genes.

Tests on vernalized seedlings. The segregation for each isolate with the positions of the parental lines ('RE714' and 'Hardi') is presented in Figure 1. At this development stage, 'RE714' was resistant and 'Hardi' was susceptible to all the isolates. The distributions were not Gaussian, but intermediate classes (i.e., classes 4,5 , and 6) were well represented. The distributions were not bimodal, so the response of the DH lines could not be simplified into resistant or susceptible types. There was a significant isolate effect and a significant interaction effect between the isolate and DH lines $(P \leq 0.01)$.

Adult plant tests. Frequencies of the virulence genes in the natural powdery mildew populations in 1997 are presented in Table 4. In both years, the powdery mildew population possessed virulence genes matching $M l R E$ and $P m 4 b$ genes. In 1997, the frequency of spores with the virulence gene matching MlRE was similar to the frequency of spores with the virulence gene matching $P m 4 b$ (between 50 and $60 \%$ ). The frequencies of spores with both virulence genes were between 30 and $40 \%$. Frequencies were similar in the hillplot and row trials (the distance between them was about $300 \mathrm{~m}$ ).

The distribution of genotypic values for AUDPC for the DH lines in 1996 and 1997 and the $F_{3}$ families in 1997 is presented in Figure 2. Since values of AUDPC were higher in the hillplot trial than in the row trial, classes for the $\mathrm{DH}$ lines were larger than for the $\mathrm{F}_{3}$ families. The severity of powdery mildew was greater in 1996 than in 1997. In the DH trials, AUDPC values were 75 and 327 for 'RE714' and 'Hardi', respectively, in 1996, and 70 and 188, respectively, in 1997. One transgressive DH line (with an AUDPC value lower than that of 'RE714') was found in 1996 and three additional DH lines were found in 1997. A significant interaction $(P \leq$ $0.01)$ between year and DH lines was detected; therefore, the results were treated separately.

For the $\mathrm{F}_{3}$ families, AUDPC values were 35 and 109 for 'RE714' and 'Hardi', respectively. Some of the $F_{3}$ families had AUDPC values as low as 'RE714' (but not significantly lower), while other $\mathrm{F}_{3}$

TABLE 5. Analysis of variance for the effects of genes $M I R E$ and $P m 4 b$ and their interaction on the area under the disease progress curve values at the adult plant stage for the double haploid lines (in 1996 and 1997) and for the $F_{3}$ families (in 1997) obtained from the cross between 'RE714' and 'Hardi'

\begin{tabular}{|c|c|c|c|c|c|c|c|c|}
\hline \multirow[b]{2}{*}{ Source } & \multicolumn{4}{|c|}{1996} & \multicolumn{4}{|c|}{1997} \\
\hline & $\mathrm{df}^{\mathrm{a}}$ & $\mathrm{F}^{\mathrm{a}}$ & $P^{\mathrm{a}}$ & $R^{2}$ & df & $\mathrm{F}$ & $P$ & $R^{2}$ \\
\hline \multicolumn{9}{|l|}{ Double haploid } \\
\hline Model $^{\mathrm{b}}$ & 3 & 7.09 & 0.0006 & 0.3471 & 3 & 6.56 & 0.0012 & 0.3601 \\
\hline MIRE & 1 & 17.71 & 0.0001 & 0.2737 & 1 & 16.16 & 0.0003 & 0.2955 \\
\hline$P m 4 b \cdot M l R E$ & 1 & 0.94 & 0.3379 & 0.0154 & 1 & 1.81 & 0.1873 & 0.0331 \\
\hline Residual & 40 & $\ldots$ & $\cdots$ & $\cdots$ & $35^{\mathrm{c}}$ & $\ldots$ & $\ldots$ & $\ldots$ \\
\hline$P m 4 b$ & 2 & 2.30 & 0.1047 & 0.0290 & & & & \\
\hline MIRE & 2 & 9.82 & 0.0001 & 0.1240 & & & & \\
\hline$P m 4 b \cdot M l R E$ & 4 & 0.88 & 0.4773 & 0.0223 & & & & \\
\hline Residual & 132 & $\ldots$ & $\ldots$ & $\ldots$ & & & & \\
\hline
\end{tabular}

${ }^{\mathrm{a}} \mathrm{df}=$ Degrees of freedom, $\mathrm{F}=$ value of Fisher, and $P=$ probability.

${ }^{\text {b }} \mathrm{F}, P$, and $R^{2}$ values are calculated with a type III model.

${ }^{c}$ For the double haploid lines in 1997, five values have been excluded because of biological problems in the field. 
families had values higher than 'Hardi'. We obtained a better evaluation of segregation with the $140 \mathrm{~F}_{3}$ families than with the $44 \mathrm{DH}$ lines.

Effects of $P m 4 b$ and $M l R E$ in the vernalized seedling resistance. Neither MIRE nor $P m 4 b$ are implicated in resistance of 'RE714' at the vernalized seedling stage against the four isolates used.

Effects of $P \boldsymbol{m} 4 \boldsymbol{b}$ and $M l R E$ in APR. A highly significant effect $(P \leq 0.01)$ of $M l R E$ on APR appeared in both the DH lines and the $\mathrm{F}_{3}$ families, whereas the effect of $P m 4 b$, alone or interacting with $M I R E$, was not significant (Table 5). $R^{2}$ for the MlRE factor was 27 and 30\% for the DH lines in 1996 and 1997, respectively, and $12 \%$ for the $\mathrm{F}_{3}$ families.

Least squares means and comparisons are shown in Table 6. For the DH lines and the $\mathrm{F}_{3}$ families, least squares means were higher in families homozygous for MlRE. Comparison of least squares means showed that the $\mathrm{F}_{3}$ families heterozygous for $M l R E$ were not significantly different (even if lower) than those homozygous for the corresponding allele of 'Hardi'.

\section{DISCUSSION}

Our test hypothesis was that the frequency of the virulence gene matching MlRE would be nearly the same as the frequency of the virulence gene matching $P m 4 b$, allowing us to compare resistance gene effects. Minimal virulence frequencies corresponding to the resistance genes $P m 4 b$ and $M l R E$ were estimated, and we observed that they were similar. Bennett (1) showed differences in the development of powdery mildew infection among seedlings that possessed the same race-specific genes. 'Hardi' (without race-specific genes and highly susceptible at the seedling stage) was used as the reference. 'Renan' has never been shown to present such a background resistance at the seedling stage. We assumed that all the spores able to develop sporulation on ' $T$. dicoccum 119' possessed at least the virulence gene matching MIRE. A background resistance, as described by Bennett (1), cannot be excluded, but would be negligible.

The strong effect detected for MIRE on APR cannot be explained only by the interaction between spores avirulent to $M I R E$ and adult plants possessing $M I R E$. Such an interaction exists also between spores avirulent to $P m 4 b$ and adult plants possessing $P m 4 b$, despite the lack of any effect of $P m 4 b$ on APR. The strong effect of MIRE shows that MIRE is involved in another kind of interaction.

$M I R E$ showed a residual expression on the genetic control of APR. A second level of interaction occurred between spores possessing virulence genes matching $M l R E$ and plants possessing $M I R E$. As no significant effect of Pm $4 b$ on APR was detected, development of spores with virulence matching $P m 4 b$ was the same on plants possessing $P m 4 b$ as on plants without the gene. Therefore, the very significant effect of $M I R E$ shows that interactions between spores with virulence matching $M l R E$ and plants possessing $M l R E$ occur and constitute the main level for the implication

TABLE 6. Least squares means of the area under the disease progress curve values at the adult plant stage for the different classes of genotype at the MIRE locus for the double haploid (DH) lines (in 1996 and 1997) and for the $\mathrm{F}_{3}$ families (in 1997) from the cross between 'RE714' and 'Hardi'

\begin{tabular}{lccc}
\hline & \multicolumn{3}{c}{ Least squares means } \\
\cline { 2 - 4 } Genotype $^{\mathrm{a}}$ & $\mathrm{DH} 1996$ & $\mathrm{DH} 1997$ & $\mathrm{~F}_{3}$ families 1997 \\
\hline MlRE/MlRE & $117.35 \mathrm{u}^{\mathrm{b}}$ & $88.51 \mathrm{w}$ & $57.80 \mathrm{y}$ \\
MlRE/o & $\ldots$ & $\ldots$ & $74.93 \mathrm{z}$ \\
o/o & $202.77 \mathrm{v}$ & $130.43 \mathrm{x}$ & $77.00 \mathrm{z}$ \\
\hline
\end{tabular}

${ }^{\text {a } M I R E / M I R E}(\mathrm{o} / \mathrm{o})=$ homozygous for $M I R E(\mathrm{o})$, and $M I R E / \mathrm{o}=$ heterozygous at the MIRE locus.

b Means followed by the same letter are not significantly different at the 0.01 probability level. of MIRE. Therefore, MIRE is involved in the genetic control of APR by reducing the development of spores that possessed the virulence gene matching $M l R E$.

This analysis of APR shows that the residual effect of a racespecific gene may occur at the adult plant stage. In this study, the residual effect of MlRE is partial and seems to be involved in the mechanisms of slow mildewing. Other authors have shown residual effects of certain race-specific resistance genes to powdery mildew in wheat. Nass et al. (15), working with near-isogenic lines at the seedling stage and with pure isolates, showed that some defeated powdery mildew resistance genes have measurable residual ability to restrict disease increase and severity. The same phenomenon has been related in other plant-pathogen systems (18). The current study is complementary and proves that the residual effect of defeated genes may occur at the adult plant stage.

The genetic control of APR to powdery mildew in 'RE714' is probably polygenic, and we have identified one of its genetic components: $M I R E$. It appeared to cause a greater variability in the $\mathrm{DH}$ lines than in the $\mathrm{F}_{3}$ families. It explained 27 and $30 \%$ of the total variation among the DH lines in 1996 and 1997, respectively, and $12 \%$ among the $\mathrm{F}_{3}$ families. The difference in results between the $\mathrm{DH}$ lines and the $\mathrm{F}_{3}$ families can be explained by the greater severity of infection in the hillplot trial than in the row trial. However, the row trial would probably be better for investigating other components of APR, because the higher number of individuals tested leads to a better partitioning of the variability.

The residual effect of MlRE on APR is essentially of a dominant-recessive kind. An advantage of the $\mathrm{F}_{3}$ families versus the $\mathrm{DH}$ lines is that they made it possible to study the dominance effects. The mean APR of the $\mathrm{F}_{3}$ families homozygous for $M I R E$ was significantly higher than those heterozygous or homozygous for the sensitive allele (Table 6). At the seedling stage, $M I R E$ was recessive and has been shown to still be recessive on APR. Quantitative analysis usually indicates the predominance of additive effects in APR $(6,10)$. However, in some crosses, APR is partially dominant (5) and interaction between these components may occur.

We have found that $P m 4 b$ has no residual effect on APR. This result is in contradiction with those of Martin and Ellingboe (13), who showed a residual effect of another allele of the same gene: $P m 4 a$. It is possible that different alleles of the same gene behave differently for residual effects. We also assume that the natural population of powdery mildew in our experiment was different, in particular, for genes of the pathogen involved in interactions of a residual type with $P m 4 a$ and $P m 4 b$.

$M l R E$ and $P m 4 b$ have no effect on VPR. This observation may be explained by two hypotheses. First, components of resistance expressed in vernalized seedling tests may be different from components of APR. The residual effect of MlRE may not be expressed at this developmental stage of the plant or in vernalized seedling test conditions. Second, the residual effect of MlRE may not be expressed with the chosen isolates. Results of our study do not permit a conclusion.

In conclusion, MlRE (but not Pm4b) has a residual effect on the quantitative resistance of wheat to powdery mildew at the adult plant stage. This effect is not observed on VPR. Other authors hypothesized that quantitative resistance could result from the combination of gene-for-gene relations (17) or from the residual effects of defeated genes (16). Our results showed that the residual effect of a race-specific gene can be a component of quantitative resistance in adult plants.

\section{ACKNOWLEDGMENTS}

We thank D. Andrivon and S. Bentley for the critical reading of the manuscript and improving the English. We thank M. Manzanares, F. Dedryver, M. Trottet, and J. Jahier for their redaction advice. We also thank C. Quandalle for donating a portion of the double haploid lines. 


\section{LITERATURE CITED}

1. Bennett, F. G. A. 1981. The expression of resistance to powdery mildew infection in winter wheat cultivars. I. Seedling resistance. Ann. Appl. Biol. 98:295-303.

2. Bennett, F. G. A. 1981. The expression of resistance to powdery mildew infection in winter wheat cultivars. II. Adult plant resistance. Ann. Appl. Biol. 98:305-317.

3. Bennett, F. G. A. 1984. Resistance to powdery mildew in wheat: A review of its use in agriculture and breeding programmes. Plant Pathol. 33:279-300.

4. Bjarko, M. E., and Line, R. F. 1988. Heritability and number of genes controlling leaf rust resistance in four cultivars of wheat. Phytopathology 78:457-461.

5. Das, M. K., and Griffey, C. A. 1994. Heritability and number of genes governing adult-plant resistance to powdery mildew in Houser and Redcoat winter wheats. Phytopathology 84:406-409.

6. Das, M. K., and Griffey, C. A. 1995. Gene action for adult plant resistance to powdery mildew in wheat. Genome 38:277-282.

7. Elen, O. N., and Skinnes, H. 1988. Partial resistance to powdery mildew in wheat seedlings. Norw. Agric. Res. 1:61-66.

8. Flor, H. H. 1955. Host-parasite interaction in flax rust-Its genetics and other implications. Phytopathology 45:680-685.

9. Griffey, C. A., Das, M. K., and Stromberg, E. L. 1993. Effectiveness of adult-plant resistance in reducing grain yield loss to powdery mildew in winter wheat. Plant Dis. 77:618-622.

10. Hautea, R. A., Coffman, W. R., Sorrells, M. E., and Bergstrom, G. C. 1987. Inheritance of partial resistance to powdery mildew in spring wheat. Theor. Appl. Genet. 73:609-615.

11. Huang, X. Q., Hsam, S. L. K., and Zeller, F. J. 1997. Chromosomal location of genes for resistance to powdery mildew in common wheat (Triticum aestivum L. em. Thell.) 4. Gene Pm24 in Chinese landrace Chiyacao. Theor. Appl. Genet. 95:950-953.

12. Lebsock, K. L., and Briggle, L. W. 1974. Gene Pm5 for resistance to Erysiphe graminis f. sp. tritici in Hope wheat. Crop Sci. 14:561-563.

13. Martin, T. J., and Ellingboe, A. H. 1976. Differences between compatible parasite/host genotypes involving the Pm4 locus of wheat and the corresponding genes in Erysiphe graminis f. sp. tritici. Phytopathology 66: 1435-1438.

14. Mcintosh, R. A., Hart, G. E., Devos, K. M., Gale, M. D., and Rogers, W. J. 1998. Catalogue of gene symbols for wheat. Pages 123-127 in: Proc. Int. Wheat Genetic Symp., 9th. Vol. 5. University Extension Press, University of Saskatchewan, Saskatoon, Canada.

15. Nass, H. A., Pedersen, W. L., MacKenzie, D. R., and Nelson, R. R. 1981. The residual effects of some "defeated" powdery mildew resistance genes in isolines of winter wheat. Phytopathology 71:1315-1318.

16. Nelson, R. R. 1978. Genetics of horizontal resistance to plant diseases. Annu. Rev. Phytopathol. 16:359-378.

17. Parlevliet, J. E., and Zadoks, J. C. 1977. The integrated concept of disease resistance: A new view including horizontal and vertical resistance in plants. Euphytica 26:5-21.

18. Pedersen, W. L., and Leath, S. 1988. Pyramiding major genes for resistance to maintain residual effects. Annu. Rev. Phytopathol. 26:369378.

19. Powers, Jr., H. R., and Sando, W. J. 1960. Genetic control of the host-parasite relationship in wheat powdery mildew. Phytopathology 50:454-457.

20. Robe, P., and Doussinault, G. 1995. Genetic analysis of powdery-mildew resistance of a winter-wheat line, RE714, and identification of a new specific-resistance gene. Plant Breed. 114:387-391.

21. Robe, P., Pavoine, M. T., and Doussinault, G. 1996. Early assessment of adult plant reaction of wheat (Triticum aestivum $\mathrm{L}$.) to powdery mildew (Erysiphe graminis f. sp. tritici) at the five-leaf seedling stage. Agronomie 16:441-451.

22. Rouse, D. I., Nelson, R. R., MacKenzie, D. R., and Armitage, C. R. 1980. Components of rate-reducing resistance in seedlings of four wheat cultivars and parasitic fitness in six isolates of Erysiphe graminis f. sp. tritici. Phytopathology 70:1097-1100.

23. Royer, M. H., Nelson, R. R., MacKenzie, D. R., and Diehle, D. A. 1984. Partial resistance of near-isogenic wheat lines compatible with Erysiphe graminis f. sp. tritici. Phytopathology 74:1001-1006.

24. Shaner, G. 1973. Evaluation of slow-mildewing resistance of Knox wheat in the field. Phytopathology 63:867-872. 